\title{
Islands stretch test for measuring the interfacial fracture energy between a hard film and a soft substrate
}

\section{Citation}

Sun, Jeong-Yun, Nanshu Lu, Kyu-Hwan Oh, Zhigang Suo, and Joost J. Vlassak. 2013. Islands Stretch Test for Measuring the Interfacial Fracture Energy Between a Hard Film and a Soft Substrate. Journal of Applied Physics 113, no. 22: 223702.

\section{Published Version}

doi:10.1063/1.4810763

\section{Permanent link}

http://nrs.harvard.edu/urn-3:HUL.InstRepos:12375010

\section{Terms of Use}

This article was downloaded from Harvard University's DASH repository, and is made available under the terms and conditions applicable to Other Posted Material, as set forth at http:// nrs.harvard.edu/urn-3:HUL.InstRepos:dash.current.terms-of-use\#LAA

\section{Share Your Story}

The Harvard community has made this article openly available.

Please share how this access benefits you. Submit a story.

\section{Accessibility}




\section{AIP Appolied Physics}

Islands stretch test for measuring the interfacial fracture energy between a hard film and a soft substrate

Jeong-Yun Sun, Nanshu Lu, Kyu-Hwan Oh, Zhigang Suo, and Joost J. Vlassak

Citation: J. Appl. Phys. 113, 223702 (2013); doi: 10.1063/1.4810763

View online: http://dx.doi.org/10.1063/1.4810763

View Table of Contents: http://jap.aip.org/resource/1/JAPIAU/v113/i22

Published by the American Institute of Physics.

Additional information on J. Appl. Phys.

Journal Homepage: http://jap.aip.org/

Journal Information: http://jap.aip.org/about/about_the_journal

Top downloads: http://jap.aip.org/features/most_downloaded

Information for Authors: http://jap.aip.org/authors

\section{ADVERTISEMENT}

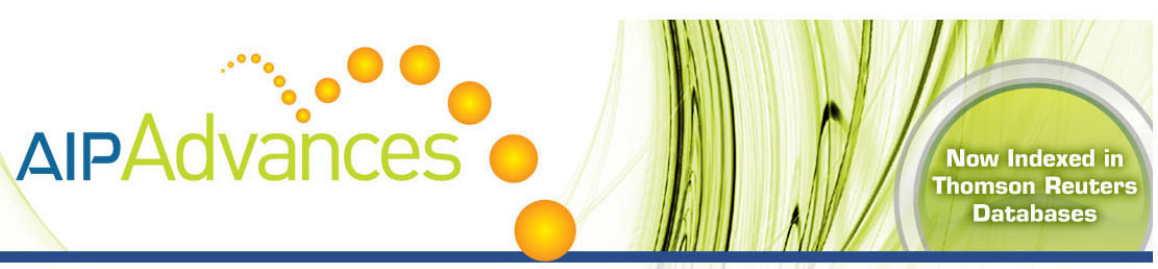

\section{Explore AIP's open access journal: Rapid publication \\ - Article-level metrics \\ - Post-publication rating and commenting}




\title{
Islands stretch test for measuring the interfacial fracture energy between a hard film and a soft substrate
}

\author{
Jeong-Yun Sun, ${ }^{1,2,3}$ Nanshu Lu, ${ }^{4}$ Kyu-Hwan Oh, ${ }^{3}$ Zhigang Suo,,${ }^{1,2}$ and Joost J. Vlassak ${ }^{1, a)}$ \\ ${ }^{1}$ School of Engineering and Applied Sciences, Harvard University, Cambridge, Massachusetts 02138, USA \\ ${ }^{2}$ Kavli Institute for Bionano Science and Technology, Harvard University, Cambridge, \\ Massachusetts 02138, USA \\ ${ }^{3}$ Department of Material Science and Engineering, Seoul National University, Seoul 151-742, South Korea \\ ${ }^{4}$ Research Center for Mechanics of Solids, Structures and Materials, Department of Aerospace Engineering \\ and Engineering Mechanics, University of Texas at Austin, Austin, Texas 78712, USA
}

(Received 31 March 2013; accepted 27 May 2013; published online 12 June 2013)

\begin{abstract}
We present a technique for measuring the interfacial fracture energy, $\Gamma_{i}$, between a hard thin film and a soft substrate. A periodic array of hard thin islands is fabricated on a soft substrate, which is then subjected to uniaxial tension under an optical microscope. When the applied strain reaches a critical value, delamination between the islands and the substrate starts from the edge of the islands. As the strain is increased, the interfacial cracks grow in a stable fashion. At a given applied strain, the width of the delaminated region is a unique function of the interfacial fracture energy. We have calculated the energy release rate driving the delamination as a function of delamination width, island size, island thickness, and applied strain. For a given materials system, this relationship allows determination of the interfacial fracture energy from a measurement of the delamination width. The technique is demonstrated by measuring the interfacial fracture energy of plasma-enhanced chemical vapor deposition $\mathrm{SiN}_{\mathrm{x}}$ islands on a polyimide substrate. We anticipate that this technique will find application in the flexible electronics industry where hard islands on soft substrates are a common architecture to protect active devices from fracture. (C) 2013 AIP Publishing LLC. [http://dx.doi.org/10.1063/1.4810763]
\end{abstract}

\section{INTRODUCTION}

Many flexible-electronics applications rely on a simple architecture that consists of a soft substrate with islands of a thin hard film. The islands contain active devices and serve to isolate these devices from any deformation of the substrate. Examples include deformable displays, eye-like cameras, and biomedical sensors. ${ }^{1-3}$ Debonding of the islands is an important reliability issue, because many of these composite structures undergo large deformation during fabrication or in use. ${ }^{4}$ The conditions for debonding have been explored for various geometric factors including island size and thickness, ${ }^{6}$ and some solutions have been suggested. For example, soft interlayers combined with plasma treatments are used to delay debonding. ${ }^{5,7}$ The lack of a reliable and convenient method for measuring the interfacial fracture energy between a hard film and a soft substrate precludes a quantitative approach to solving this problem.

Quantitative experimental techniques for measuring $\Gamma_{i}$ in thin-film systems are limited, because it is generally difficult to introduce well-defined interface pre-cracks and to apply precise loads. ${ }^{8}$ Classical techniques include the peel test, ${ }^{9,10}$ the double cantilever beam test, ${ }^{11}$ and the four-point bend test. ${ }^{12}$ These methods often employ steady-state conditions because the mechanics is simpler and accurate measurement of the crack length is not required. These techniques are widely used in the microelectronics industry.

a)email: vlassak@seas.harvard.edu
They are, however, not readily applicable to flexible electronics: the substrates used for flexible electronics are too compliant to generate significant crack extension forces in the four-point bend or the double cantilever beam tests, while the peel test may result in large-scale yielding, which makes quantitative interpretation of the results quite difficult. Furthermore, the peel test has a mode mixity that differs in sign and magnitude from the mode mixity associated with most practical decohesion problems. ${ }^{13}$

In terms of non-steady-state measurements of interfacial toughness, He, Evans, and Hutchinson analyzed the convergent debonding problem using finite elements, and found that the interfacial cracks begin to sense the edge of the film when the length of the remaining bonded interface is approximately 5-40 times the film thickness. ${ }^{14}$ They suggested that quantitative statements could be made about $\Gamma_{i}$ by measuring the distance between the edge and the arrested crack tip, but this approach was never developed into a practical technique for measuring the adhesion of very thin films. Here, we describe a technique for measuring interfacial fracture energy in which a soft substrate with a periodic array of hard thin islands is subjected to uniaxial tension under an optical microscope. When the applied strain reaches a critical value, delamination between the islands and the underlying substrate starts from the edge of the islands. As the strain increases, the interfacial cracks grow in a stable fashion. At a given applied strain, the width of the delaminated region is a unique function of the interfacial fracture energy. Using the finite element method (FEM), we have calculated the energy 
(a)

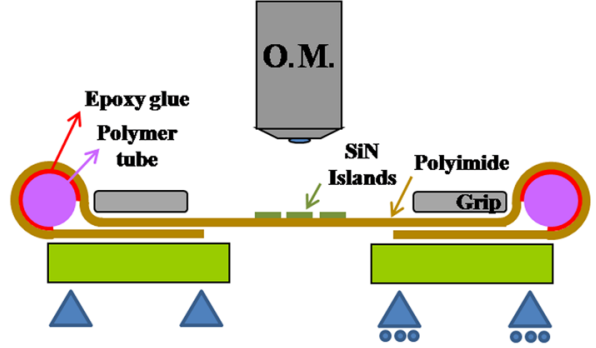

(c)

(b)
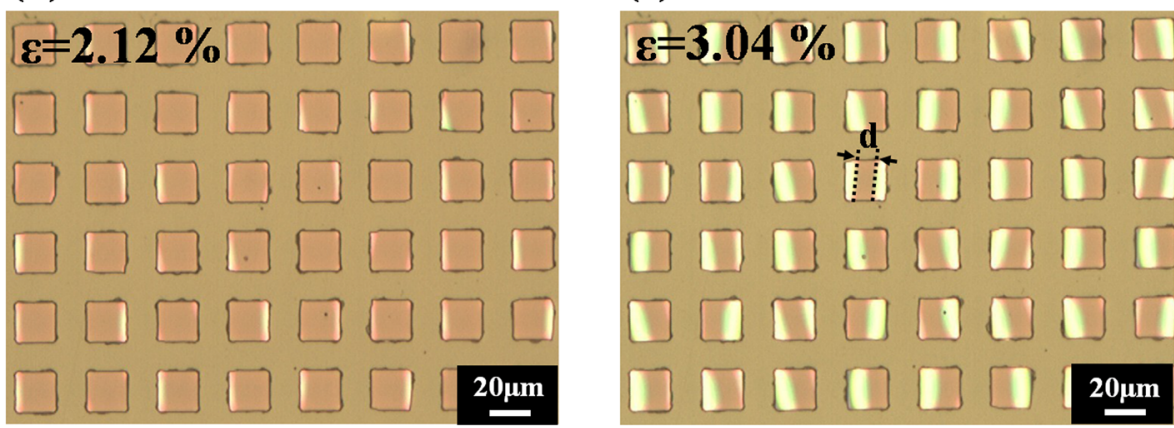

FIG. 1. An array of $\mathrm{SiN}_{\mathrm{x}}$ islands on a PI substrate stretched in uniaxial tension. (a) Schematic of the in-situ tensile test system under an optical microscope; (b) and (c) Micrographs of $500 \mathrm{~nm}$ thick $\mathrm{SiN}_{\mathrm{x}}$ islands $20 \mu \mathrm{m}$ in size, subjected to (b) $2.12 \%$, (c) $3.04 \%$ strain. The ligament length, $d$, is measured as a function of applied strain as indicated in the figure. release rate driving the delamination as a function of delamination width, island size, island thickness, and applied strain. For a given materials system, this relationship can be used to determine the interfacial fracture energy from a measurement of the delamination width. We present results obtained for $\mathrm{SiN}_{\mathrm{x}}$ islands (see Fig. 1(a)) on polyimide (PI) substrates.

\section{EXPERIMENTAL}

We have fabricated periodic $\mathrm{SiN}_{x}$ islands on $25 \mu \mathrm{m}$ thick PI substrates (Upilex-S, UBE Industries) using techniques that have been described previously, ${ }^{5,6}$ combined with the following lift-off procedure: The PI substrates were ultrasonically cleaned using methanol and acetone and attached to a $3 \mathrm{~mm}$ thick aluminum (Al) plate using double-sided tape. The PI/Al assemblies were kept in a vacuum chamber for $24 \mathrm{~h}$ to eliminate any air bubbles. A 3.2- $\mu \mathrm{m}$-thick positive photoresist (S1818, Microposit) was then spin-coated on top of the PI substrates. The coated substrates were baked for $2 \mathrm{~min}$ at $115^{\circ} \mathrm{C}$ and exposed for $3 \mathrm{~s}$ through a chromium reticule using an MJB4 mask aligner (SUSS MicroTec) with a G-line light intensity of $59.1 \mathrm{~mW} / \mathrm{cm}^{2}$. The samples were developed in a MF-319 photoresist developer (Microposit), rinsed in DI water for $1 \mathrm{~min}$, and dried with $\mathrm{N}_{2}$ gas. The PI substrates were then cut into $7 \mathrm{~mm} \times 60 \mathrm{~mm}$ rectangular strips while still attached to the Al plate. Low-stress $\mathrm{SiN}_{x}$ films, with a residual stress smaller than $20 \mathrm{MPa}$, were deposited by plasma-enhanced chemical vapor deposition (PECVD) in a NEXX system with a base pressure of $5 \times 10^{-6}$ Torr. The depositions were performed at a working pressure of 10 mTorr and with gas flows of $40 \mathrm{sccm}$ of Ar$3 \% \mathrm{SiH}_{4}, 5.8 \mathrm{sccm}$ of $\mathrm{N}_{2}$, and $20 \mathrm{sccm}$ of pure Ar. A microwave power of $265 \mathrm{~W}$ was used during the depositions and the substrate temperature was maintained at $22^{\circ} \mathrm{C}$. After deposition, the $\mathrm{SiN}_{x}$ coatings were patterned by stripping the photoresist along with the extra $\mathrm{SiN}_{\mathrm{x}}$ in acetone. Samples with square islands of width $L$ ranging from $20 \mu \mathrm{m}$ to $40 \mu \mathrm{m}$ and of thickness $h$ ranging from $500 \mathrm{~nm}$ to $1 \mu \mathrm{m}$ were prepared. The island pitch $S$ was held constant at $1.5 \times L$ for all specimens.

After removing the samples from the Al plate, they were uniaxially stretched in a screw-driven tensile device as shown schematically in Fig. 1(a). A $5 \mathrm{~mm} \times 5 \mathrm{~mm}$ square array of islands was placed in the middle of the two grips to achieve a uniform tensile state. All tensile tests were performed under an optical microscope with a CCD camera. Applied strains were measured directly on recorded micrographs by comparing initial and current average island spacings.

\section{EXPERIMENTAL RESULTS}

The optical images in Figs. 1(b) and 1(c) show a typical array of $\mathrm{SiN}_{\mathrm{x}}$ islands subjected to two different levels of strain. The bright fringes in the figures are caused by the presence of an air gap between the island and the substrate, ${ }^{15}$ and they indicate where the islands have debonded from the substrate. A fringe typically starts at the edge of an island when the applied strain reaches a critical value, denoted by $\varepsilon_{c}$, and propagates more or less parallel to the edge of the island as the applied strain is increased. Both one-sided (symmetric) and two-sided (asymmetric) debondings are observed at a given strain level, but all islands show a similar ligament length $d$ regardless of whether debonding is one- or two-sided. We define the total debond length as the difference between island side and ligament length, $2 a=L-d$. The issue of debonding symmetry is further explored in Sec. V.

Figure 2 shows the total debond length as a function of applied strain for various island dimensions. It is evident from the figure that the critical strain for the onset of debonding is quite small and that it increases with decreasing island size and thickness. After the onset of debonding, the total debond length initially increases proportionally with 


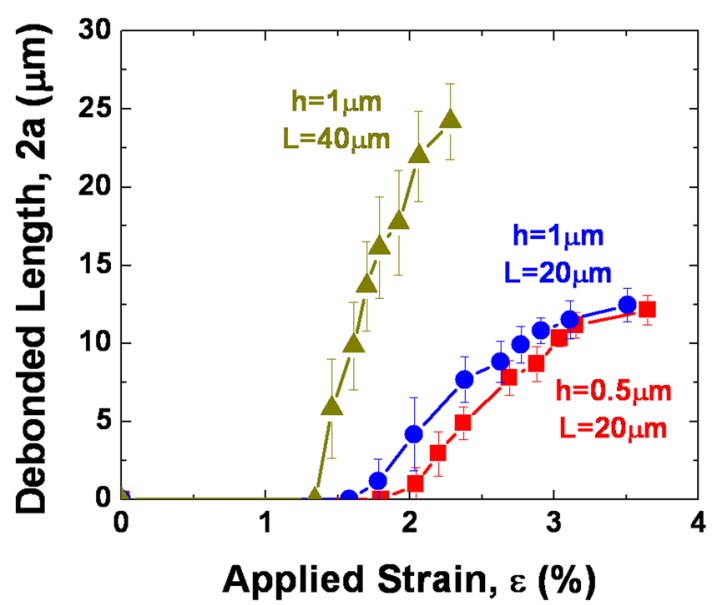

FIG. 2. The delaminated lengths of the stretched islands are measured experimentally as a function of applied strain. The delaminated length is defined as the island size minus the ligament length $(2 a=L-d)$.

increasing applied strain and saturates as it approaches the width of the island. We determine the interfacial toughness $\Gamma_{i}$ from the total debond length in the linear regime.

\section{ANALYTICAL RESULTS}

If a thin film delaminates from a substrate and the tip of the interfacial crack is sufficiently far away from the edge of the film, the energy release rate is independent of crack length and is given by

$$
G_{s s}=\frac{\left(1-\nu_{\mathrm{f}}^{2}\right) \sigma_{0}^{2} h}{2 E_{f}},
$$

where $E_{f}$ is Young's modulus of the film, $\nu_{f}$ is Poisson's ratio of the film, $\sigma_{0}$ is the film stress, and $h$ is the film thickness. This expression represents the elastic energy per unit area released under plane-strain conditions. If the energy release rate is greater than the interfacial fracture energy at the relevant mode mixity, $\Gamma_{i}$, spontaneous delamination will occur given a sufficiently long initial crack. ${ }^{16}$ Since the energy release rate is independent of crack length, delamination of the film proceeds indefinitely.

If, on the other hand, a debond crack converges onto the edge of the film or another debond, the crack begins to relax the strain energy stored in the attached segment of the film. This occurs over remarkably large distances, where the attachment width $d$ is still many times the film thickness. ${ }^{14}$ As a consequence, the energy release rate drops below the steady-state value, even when $d / h$ is quite large. This gradual decrease in energy release rate was exploited in Ref. 17 to measure the interface fracture energy of films that had been stressed to the point where $G_{s s}$ exceeded the interfacial fracture energy. He et al. ${ }^{14}$ carried out finite element calculations for convergent debonding of thin films. They also found an analytical solution for the case where cracks from two opposing edges of an island approach each other in the limit that the remaining bonded interface is very short. In this case, both film and substrate can be considered as half planes and the energy release rate is given by

$$
G=\frac{\pi}{16}\left(\varepsilon_{\text {app }}\right)^{2}(L-2 a)\left(\frac{1}{E_{s}^{*}}+\frac{1}{E_{f}^{*}}\right)^{-1},
$$

where $E^{*}=E /\left(1-\nu^{2}\right)$ and $\varepsilon_{a p p}$ is the strain applied to the substrate.

If there is a residual stress $\sigma_{r e}$ in the film, we show that the effect of the residual stress is similar to that of an additional substrate strain (Fig. 3). The energy release rate in the presence of a residual stress in the film is given by

$$
G=\frac{\pi}{16}\left(\frac{\sigma_{r e}}{E_{f}^{*}}+\varepsilon_{a p p}\right)^{2}(L-2 a)\left(\frac{1}{E_{s}^{*}}+\frac{1}{E_{f}^{*}}\right)^{-1}
$$

If the substrate is much more compliant than the island, $E_{s} \ll E_{f}$, Eq. (3) reduces to

$$
G=\frac{\pi}{16} E_{s}^{*}\left\{\frac{\sigma_{r e}}{E_{f}^{*}}+\varepsilon_{a p p}\right\}^{2}(L-2 a) .
$$

When the substrate is very compliant, Eq. (4) fits the energy release rate obtained from FEM calculations well over the entire range of crack lengths. ${ }^{18}$ This result is understood as follows. When $E_{s} \ll E_{f}$, the film is nearly rigid, and the thickness of the film does not affect the elastic field in the substrate, so that the energy release rate is independent of the thickness of the film. Thus, an approximate value of the interfacial fracture energy can be calculated from the applied strain and the experimental ligament lengths without resorting to full computational simulations.

\section{COMPUTATIONAL RESULTS}

Using the commercial finite element code ABAQUS, we have constructed two plane-strain models to analyze the delamination of an array of thin-film islands from a substrate: one model represents symmetric, the other asymmetric debonding. Schematic views of the unit cells of the models are shown in Figs. 4(a) and 4(b). For the symmetric debonding model, two interfacial cracks of length " $a$ " were introduced at each edge of the island; for the asymmetric model, one crack of length " $2 a$ " was introduced at one of the edges. The islands and the substrate were taken as homogenous, isotropic, linear elastic solids with Young's moduli $E_{\mathrm{SiNx}}=200 \mathrm{GPa}$ and $\mathrm{E}_{\mathrm{PI}}=9.2 \mathrm{GPa}$, and Poisson's ratios $\nu_{\mathrm{SiNx}}=\nu_{\mathrm{PI}}=0.3$. A uniform displacement $u_{\text {appl }}$ was applied to the substrates in the $x_{1}$-direction, i.e., the applied strain was given by $\varepsilon_{\text {appl }}=2 u_{\text {appl }} / S$. In the absence of a residual stress, dimensional considerations dictate that the energy release rate should take the following form:

$$
G=\frac{E_{s}^{*} \varepsilon_{a p p}^{2} L}{2} g\left(\frac{a}{L}, \frac{H}{L}, \frac{h}{L}\right)
$$

where $g$ is a dimensionless function that can be determined using finite elements and $H$ is the thickness of the substrate.

The energy release rates of the interface cracks for symmetric and asymmetric crack propagation are plotted as a function of interfacial crack length in Fig. 4(c). $H / L$ and $h / L$ are 
(a)

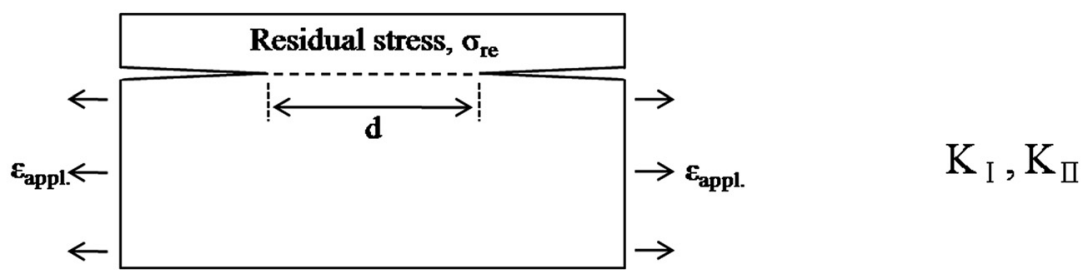

II

(b)

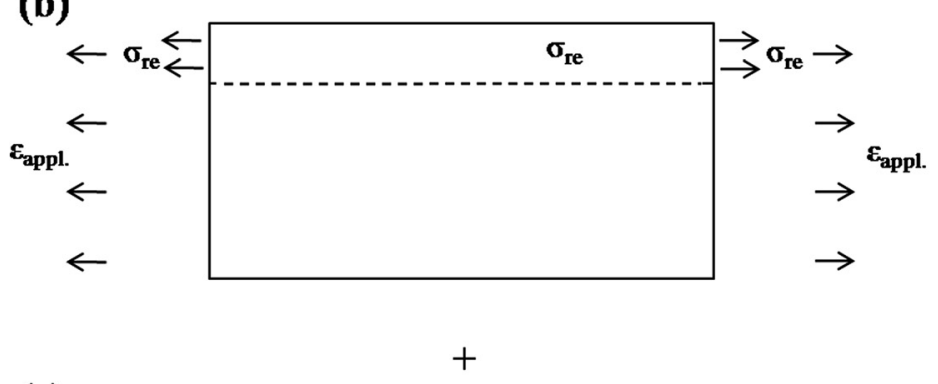

$$
\mathrm{K}_{\mathrm{I}}=\mathrm{K}_{\square}=0
$$

$\mathrm{K}_{\mathrm{I}}, \mathrm{K}_{\mathrm{I}}$

$$
\mathrm{K}_{\mathrm{I}}, \mathrm{K}_{\square}
$$

FIG. 3. A residual stress in the film can be accompanied with an applied strain in the substrate. (a) The interface stress intensity factors in mode I and mode II loading, $\mathrm{K}_{\mid}, \mathrm{K}_{\|}$, are affected by both residual stress in the film and applied strain in the substrate. (b) The interface stress intensity factors $\mathrm{K}_{\mid}$and $\mathrm{K}_{\|}$are zero because there is no strain mismatch across the interface. (c) The interface stress intensity factors in this state are same as in state (a).

(c)

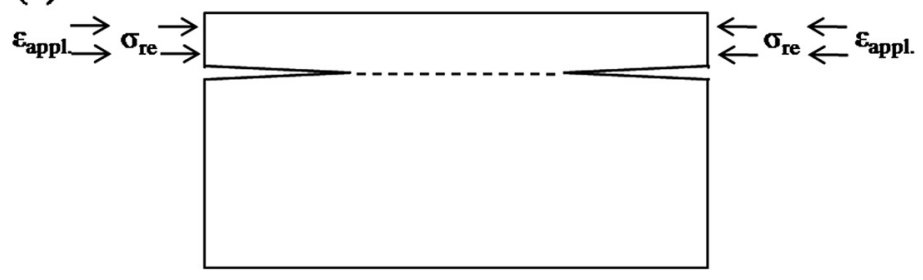

fixed at 1.25 and 0.05 , respectively, in this figure. As shown in Fig. 4(c), symmetric and asymmetric debondings show identical energy release rates if the ligament lengths are the same. Furthermore, the energy release rate is very close to the value given by the analytic solution for convergent debonding. Thus, there is no need to distinguish between symmetric or asymmetric debonding when using this approach to measure the interfacial energy; it is sufficient to measure the ligament length as a function of the applied strain. The energy release rate can be calculated using the analytic expression or derived from the FEM simulations if better accuracy is required. In the limit of no pre-crack, i.e., $2 a=0$, the energy release rate is zero, but it rises sharply with crack length to reach a maximum at a length that is significantly smaller than the film thickness.

A direct consequence of the maximum in the energy release rate is that there exists a critical applied strain at (a)

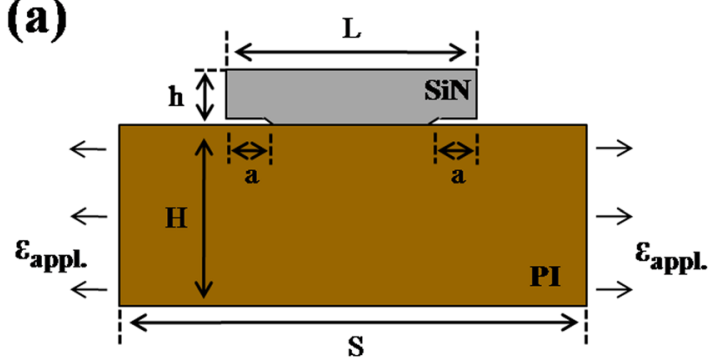

(b)

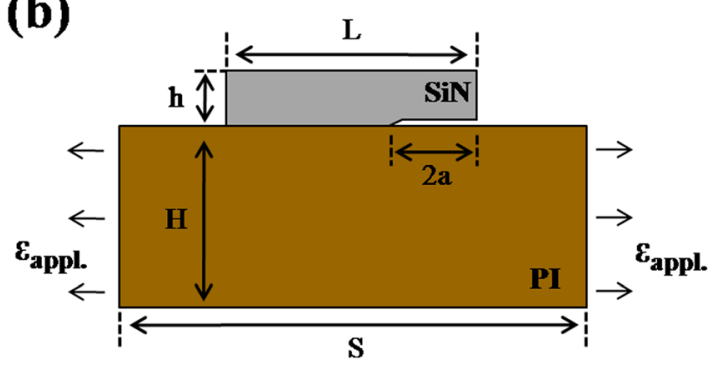

(c)

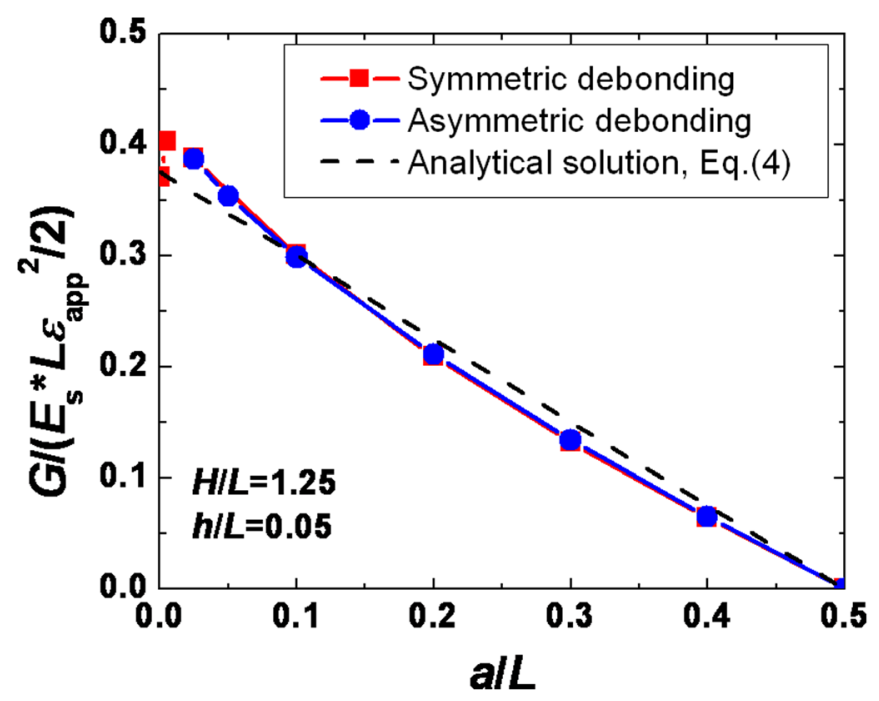

FIG. 4. Plane strain models of (a) symmetric, (b) asymmetric debonding propagation. $S / L=1.5$ is fixed in all the experiments and simulations. (c) The normalized energy release rate is plotted as a function of the normalized debonded length. Symmetric and asymmetric debondings show almost the same energy release rate when the ligament size is the same. 
(a)

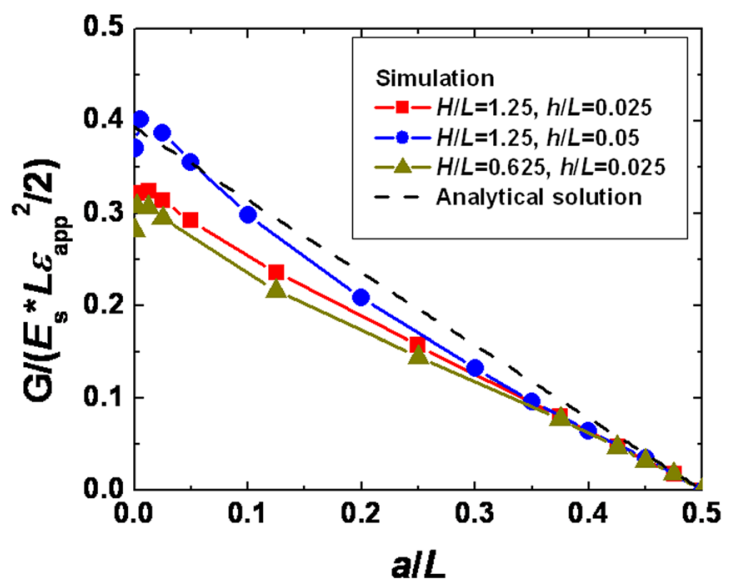

(b)

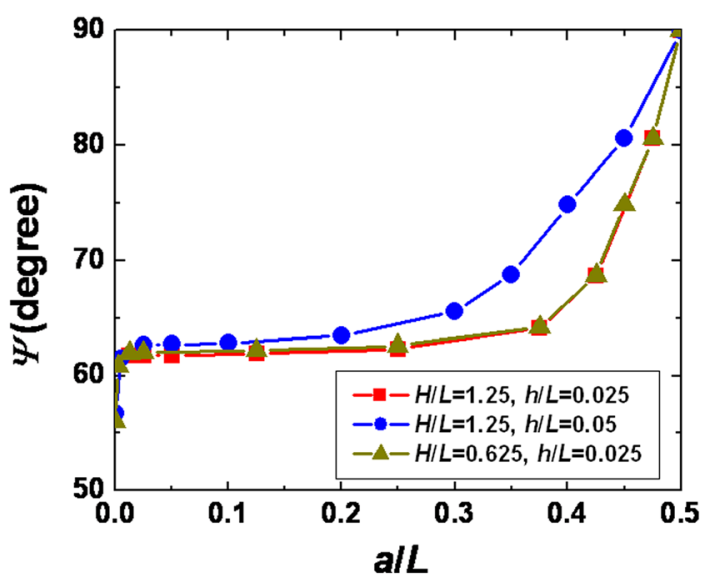

FIG. 5. FEM results of (a) normalized energy release rate and (b) mode angle as a function of debonded length for symmetric debonding. The energy release rates for convergent debonding (Eq. (4)) are shown by the dashed lines.

which the maximum value of the energy release rate is equal to interfacial fracture energy. Once the strain in the substrate reaches this critical value, the islands start to delaminate. When the substrate is strained further, the debond cracks continue to grow, but they grow in a stable fashion because the energy release rate decreases with increasing crack length — cracks arrest as soon as the energy release rate drops below interfacial fracture energy, $\Gamma_{i}$. Thus, the experimentally measured debond length can be converted into an energy release rate using either the FEM simulations or the analytical solution given by Eq. (4), which in turn is equal to the interfacial fracture energy.

Figure 5(a) plots the energy release rate as a function of debond crack length for the case of symmetric debonding. Curves are shown for various values of island and substrate thickness. The energy release rate increases and approaches the analytical prediction given by Eq. (4) as the value of $h / L$ increases; by contrast the effect of $H / L$ is relatively small. Because large islands crack rather than debond, ${ }^{6}$ the ratio of island thickness to island size cannot be decreased below $h / L=0.025$, thus establishing an upper bound of approximately $21 \%$ on the error associated with using the analytical expression. As pointed out by Lu et al., ${ }^{18}$ this error is further reduced as the compliance of the substrate increases. For instance, $\mathrm{SiN}_{\mathrm{x}}$ islands on a PDMS substrate, $E_{S} / E_{f}=0.001$, have an energy release rate that differs less than $5 \%$ from the analytical prediction.

The mode angle of the interface crack, $\psi$, is defined by the ratio of the stress intensity factors under shear and normal loading conditions

$$
\tan \psi=\frac{K_{\|}}{K_{\mid}},
$$

where $K_{\mid}$and $K_{\|}$are the stress intensity factors for mode | and mode || loading, respectively. Figure 5(b) plots the mode angle as a function of crack length for various island sizes and thicknesses. The mode angle is nearly constant for crack lengths below $25 \%$ of the island size and increases rapidly for longer cracks-debonding becomes progressively shear dominated.

\section{MEASURING THE INTERFACIAL FRACTURE ENERGY}

Here, we further pursue the idea that when the relation between energy release rate $G$ and crack length is known, quantitative conclusions about $\Gamma_{i}$ can be drawn from measurements of the distance between the edge and the arrested crack tip. By combining the results in Figs. 2 and 5, the fracture energy for the interface between the $\operatorname{SiN}_{\mathrm{x}}$ film and the PI substrate can be calculated. When the strain applied to the substrate exceeds the critical value, interfacial cracks form and grow in a stable fashion, such that at any given substrate strain the energy release rate is equal to the interfacial fracture energy. Thus, the debond crack length associated with the applied strain in Fig. 2 can be directly converted into a fracture energy using the data in Fig. 5. The resulting interfacial fracture energies, and the corresponding mode angles, are plotted in Fig. 6. The values of the fracture energy are independent of film thickness or island size, which provides confirmation of the measurement technique, and increase slightly with applied strain. Note that the energies calculated using the FEM models have a very tight distribution. Those obtained from the analytical expression are not quite as tight, but still provide a reasonable measure for the fracture energy for many practical applications. The experimental values of the fracture energy lie in the $10-15 \mathrm{~J} / \mathrm{m}^{2}$ range, which is consistent with values estimated from the scotch-tape peel test and the fragment test. ${ }^{15,19}$ The mode angle increases slightly with increasing strain, and this change may be associated with the slight increase in fracture energy observed in Fig. 6(a). An increase of the fracture energy with increased mode angle has also been observed for the plexiglass/epoxy system. ${ }^{13}$

The technique is ideal for use in the field of flexible electronics because it makes use of an architecture that is routinely used in these applications, i.e., the device itself can be used to measure the interfacial toughness without preparing extra testing samples. Since debonding of many islands can be observed at the same time, the technique lends itself for statistical analysis. The analytical solution, Eq. (4), for 
(a)

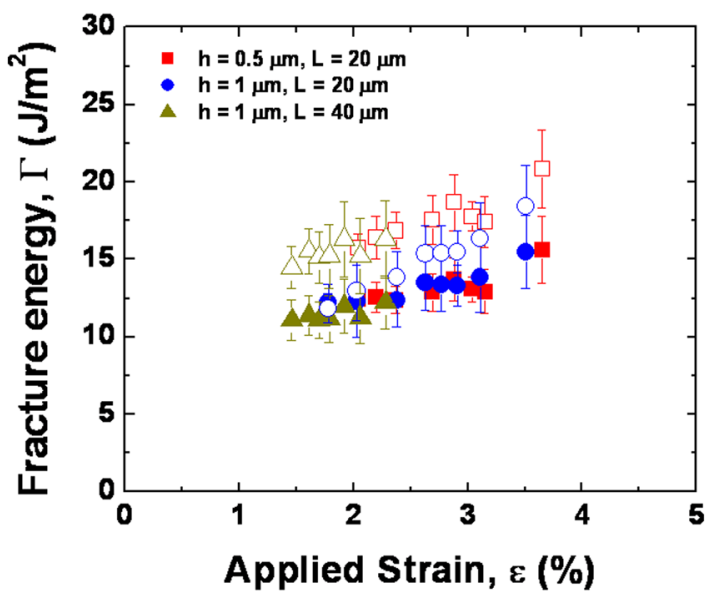

(b)

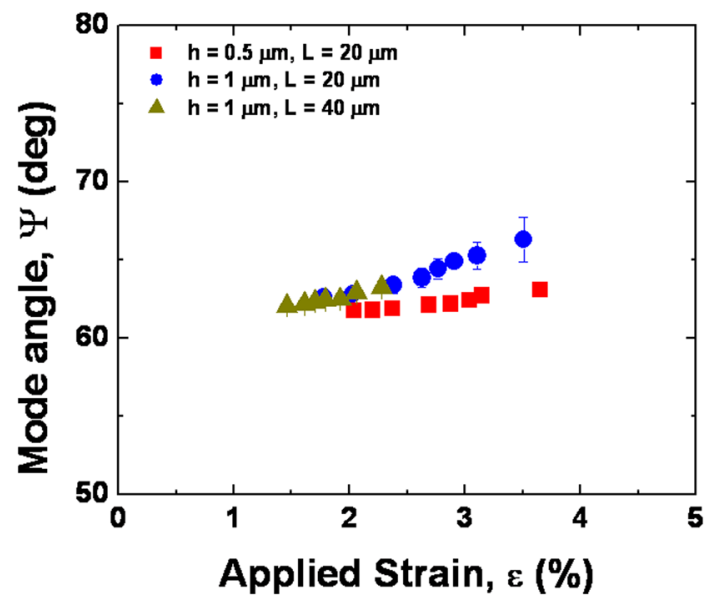

FIG. 6. Combining Figs. 2 and 5, (a) the interfacial toughness between $\mathrm{SiN}_{\mathrm{x}}$ islands and polyimide substrate and (b) the mode angle are plotted as a function of applied strain for various island thicknesses and island sizes. The open symbols in (a) are calculated from Eq. (4) and the filled symbols are calculated from the computed energy release rate. Very consistent interfacial toughness and mode angle are obtained regardless of island size, island thickness, and applied strain.

the convergent debonding problem is in good agreement with more accurate FEM calculations, and Eq. (4) can be used to obtain approximate values of the interface fracture energy from measurements of the ligament length and the applied strain.

\section{CONCLUDING REMARKS}

A technique for measuring the interface adhesion energy $\Gamma_{i}$ of hard thin films on soft substrates has been devised, analyzed, and demonstrated. When subject to uniaxial stretching, stiff ceramic islands on soft polymeric substrates exhibit debonding. Debond lengths of each island are measured as a function of applied strain, while the relationship between energy release rate and debond length is calculated using the finite element method. By combining the experimental debond length and the FEM results, the fracture energy of the interface can be calculated. We have also developed an approximate analytical expression, Eq. (4), for energy release rate, which can be used to convert the observed ligament length to the fracture energy for most practical purposes. The technique is ideal for use in the field of flexible electronics because it makes use of an architecture that is routinely used in these applications and lends itself for statistical analysis because debonding of many islands can be observed at the same time.

\section{ACKNOWLEDGMENTS}

This research was performed in part at the Center for Nanoscale Systems at Harvard University, which is supported by the National Science Foundation under Award No. ECS-0335765. Financial support from the National Science Foundation under Grant DMR-0906892 and under Grant DMR-0820484 (MRSEC) is also gratefully acknowledged.
K.H.O is grateful for the support from National Research Foundation of Korea (NRF) funded by the Ministry of Education, Science and Technology (R11-2005-065).

${ }^{1}$ J. A. Rogers, Z. Bao, K. Baldwin, A. Dodabalapur, B. Crone, V. R. Raju, V. Kuck, H. Katz, K. Amundson, J. Ewing, and P. Drzaic, Proc. Natl. Acad. Sci. U.S.A. 98, 4835 (2001).

${ }^{2}$ H. C. Ko, M. P. Stoykovich, J. Song, V. Malyarchuk, W. M. Choi, C.-J. Yu, J. B. Geddes, J. Xiao, S. Wang, Y. Huang, and J. A. Rogers, Nature 454, 748 (2008).

${ }^{3}$ D.-H. Kim, J. Viventi, J. J. Amsden, J. Xiao, L. Vigeland, Y.-S. Kim, J. A. Blanco, B. Panilaitis, E. S. Frechette, D. Contreras, D. L. Kaplan, F. G. Omenetto, Y. Huang, K.-C. Hwang, M. R. Zakin, B. Litt, and J. A. Rogers, Nature Mater. 9, 511 (2010).

${ }^{4}$ R. Bhattacharya, A. Salomon, and S. Wagner, J. Electrochem. Soc. 153, G259 (2006).

${ }^{5}$ J.-Y. Sun, N. Lu, J. Yoon, K.-H. Oh, Z. Suo, and J. J. Vlassak, J. Mater. Res. 24, 3338 (2009).

${ }^{6}$ J.-Y. Sun, N. Lu, J. Yoon, K.-H. Oh, Z. Suo, and J. J. Vlassak, J. Appl. Phys. 111, 013517 (2012).

${ }^{7}$ T.-G. Woo, I.-S. Park, K.-H. Jung, W.-Y. Jeon, Y.-K. Hwang, and K.-W. Seol, Electron. Mater. Lett. 8, 151 (2012).

${ }^{8}$ A. Bagchi and A. G. Evans, Interface Sci. 3, 169 (1996).

${ }^{9}$ K.-S. Kim and N. Aravas, Int. J. Solids Struct. 24, 417 (1988).

${ }^{10}$ K.-S. Kim and J. Kim, J. Eng. Mater. Technol. 110, 266 (1988).

${ }^{11}$ Z. Suo and J. W. Hutchinson, Mater. Sci. Eng. A 107, 135 (1989).

${ }^{12}$ G. Charalambides, J. Lund, A. G. Evans, and R. M. McMeeking, J. Appl. Mech. 56, 77 (1989).

${ }^{13} \mathrm{~J}$. W. Hutchinson and Z. Suo, "Mixed Mode Cracking in Layered Materials," in Advances in Applied Mechanics, Vol. 29 (Academic Press, 1992), pp. 63-191.

${ }^{14}$ M. Y. He, A. G. Evans, and J. W. Hutchinson, Acta Mater. 45, 3481 (1997).

${ }^{15}$ S. Tarasovs, J. Andersons, and Y. Leterrier, Acta Mater. 58, 2948 (2010).

${ }^{16}$ H. H. Yu, M. Y. He, and J. W. Hutchinson, Acta Mater. 49, 93 (2001).

${ }^{17}$ A. V. Zhuk, A. G. Evans, J. W. Hutchinson, and G. M. Whitesides, J. Mater. Res. 13, 3555 (1998).

${ }^{18}$ N. Lu, J. Yoon, and Z. Suo, Int. J. Mater. Res. 2007/08, 717 (2007).

${ }^{19}$ H. Li, R. K. Sharma, Y. Zhang, A. A. O. Tay, E. T. Kang, and K. G. Neoh, Langmuir 19, 6845 (2003). 